\title{
ORIGIN AND ALTERATION OF ORGANIC MATTER OF THE OXFORD CLAY FORMATION (U.K.) DETERMINED FROM BULK GEOCHEMICAL ANALYSES
}

KENIG, Fabien, Biogeochemical Laboratories, Geology Bldg., Indiana University, Bloomington, IN 47405, U.S.A.; POPP*, Brian, Dept of Geology and Geophysics, University of Hawaii, Honolulu, HI 96822, U.S.A; SUMMONS, Roger, Bureau of Mineral Resources, P.O. Box 378, Camberra, 2601, AUSTRALIA.

To understand the processes controlling production, accumulation, and preservation of organic matter in the Lower Oxford Clay (LOC), we determined the hydrogen index (HI), the oxygen index (OI), the Tmax (from Rock-Eval), the content of total organic carbon (TOC), total carbon and total sulfur, and the carbon isotopic composition of bulk organic matter from 160 samples collected from 6 different quarries and one continuous core. With concentrations of TOC varying between $0.5 \%$ and $16.6 \%$, the LOC is an organic-rich shale. For samples dominated by organic matter of phytoplanktonic origin, the hydrogen and oxygen indices and the $\operatorname{Tmax}\left(\sim 418^{\circ} \mathrm{C}\right)$ indicate low levels of maturity, and, thus, the shallow burial of the LOC through geologic time.

Two main sources of organic matter can be distinguished: a major phytoplanktonic source with high $\mathrm{HI}$ and low $\mathrm{OI}$ and a minor terrestrial source with low HI and high OI. A third group, represented by samples with low HI and low OI, consists mainly of altered materials from the Middle Oxford Clay and the LOC. Selection of samples for chemical analysis was based on the macrofaunal assemblages defined by Duff (1975). These various biofacies are characterized by specific organic geochemical features indicating the relationship between conditions affecting faunal assemblages and those controlling accumulation and preservation of organic matter. For example, Duff's 'deposit feeder shales', which are dominated by epifaunal bivalves and are depleted in infaunal organisms, exhibit the highest concentration and best preservation of marine organic matter, with an average TOC of $6.8 \%$ for 56 samples analyzed. The preservation of such organic matter requires a dysaerobic water column and a high sedimentation rate.

Carbon isotopic compositions within the 'deposit feeder shale' biofacies (-27.6 to -23.2\%o) appear to have been controlled by the intensity of primary productivity. The highest-TOC, marine-dominated, ${ }^{13} \mathrm{C}$-rich samples reflect photosynthetic drawdown of dissolved- $\mathrm{CO}_{2}$ level, and, thus, originated in highly productive environments. On the other hand, variations in the carbon isotopic composition of organic matter in shell beds $(-27.5$ to $-26 \%$ o) probably reflect heterotrophic reworking of the organic matter, winnowing of the sediments, and mixing with a source of organic matter enriched in ${ }^{13} \mathrm{C}$, such as wood $\left(\delta^{13} \mathrm{C}\right.$ from -25 to $-23 \%$ ). Such mixing phenomena may also explain the high variability of the carbon isotopic compositions of TOC-depleted and altered samples from the Middle and Upper Oxford Clay.

The environment of deposition of the LOC would be characterized by the alternation of two major conditions: 1) periods of high productivity, dysoxic water column and high sedimentation rate leading to the development of organic-rich shales dominated by phytoplanktonic organic matter, and 2) periods of low productivity, oxic water column and high current activity implying winnowing and alteration of organic matter, and leading to the formation of shell beds where marine and terrestrial organic matter are mixed. 